\title{
Wayne Manufacturing: A Teaching Case On The Detection Of Misappropriation Of Assets
}

Lou X. Orchard, (Email: Lou.Orchard@wichia.edu), Wichita State University Jeffrey L. Decker, University of Illinois, Springfield

Tim Kizirian, California State University, Chico

\begin{abstract}
This paper is a teaching case intended for use in an undergraduate auditing or fraud examination course. Students are introduced to Wayne Manufacturing, a medium-sized firm in the Midwestern U.S.A. that manufactures parts for companies such as General Motors (GM) and Ford. Wayne Manufacturing has some conditions present that put it at risk for misappropriation of assets. Since it is not infrequent that such misappropriations are concealed in the accounting records, these conditions also increase the risk of fraudulent financial reporting. Section One presents the facts of the case. Section Two presents decision-guiding questions for students to consider. Section Three provides teaching notes. Section Four provides a summary of the paper.
\end{abstract}

\section{CASE FACTS}

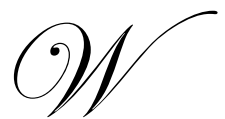

ayne Manufacturing Incorporated (WM) has been in business since 1931, having grown from a twoman operation on the south side of Fort Wayne, Indiana to a $\$ 675$ million, publicly-traded business with facilities in Fort Wayne, Benton Harbor, Michigan and Troy, Alabama. A total of 1,030 people work for Wayne Manufacturing in its three facilities. WM has been a consistent supplier to the automobile industry as well as spot work for the aircraft industry, and even several space shuttle projects. They have been an audit client of your CPA firm for 27 years, a result of the merging of public accounting firms over the years.

Wayne Manufacturing operates in a highly competitive industry. Its main customers, GM and Ford, are both facing increasingly uncertain futures, with market share down and operating losses mounting. GM has begun selling off assets such as their stake in Subaru and Suzuki in order to raise funds to finance a turnaround. Ford has scaled back operations and sales of new models are not meeting expectations (e.g., the Ford 500).

Within the industry, WM's main U.S. competitors, such as Dana Corporation and Visteon Corporation, are either in bankruptcy or cutting back on expenditures by reducing employee benefits. Competitors from Asia are currently grabbing market share and applying pressure to American firms such as WM. After-market retailers such as Car Quest, AutoZone, and NAPA are searching for manufacturing partners in Asia, particularly China, as many replacement components for automobiles are sold strictly on a cost-competitive (rather than feature-competitive) basis.

Charles "Chuck" Wilson, CEO of WM, has responded to the increasingly competitive environment by instructing members of his management team to actively seek out ways to cut costs. WM is not in immediate danger of entering bankruptcy, but it is a potential target for acquisition by foreign firms (e.g., Korean and Australian firms have been actively searching for and inquiring about firms in the automobile component industry for possible takeover).

WM reported a $\$ 27$ million profit on sales of $\$ 675$ million, or a $4 \%$ profit on sales. This is down from $6.5 \%$ five years ago, with Wilson citing increased cost of goods sold and cuts in selling prices as the main reasons. The 
company has borrowed $\$ 75$ million to renovate the Fort Wayne facility. WM has a long history of 25 cent per share quarterly dividends on outstanding shares of common stock (currently 1 million shares are outstanding), a trend that CEO Wilson is determined to continue.

Wilson has been with the company 27 years, the last 15 as CEO. He owns about $6 \%$ of the common stock and sits on the Board of Directors. He currently earns an annual salary of $\$ 300,000$ plus bonus. Bonuses are typically $8 \%$ to $10 \%$, and can range from zero to $15 \%$. He is well liked in the Fort Wayne community. He likes to travel, and owns homes in Fort Wayne, Los Angeles, Acapulco, Mexico and Venice, Florida. His wife, Diane, doesn't work outside the home, but is active in many community oriented events and stays busy with their three children. Both Charles and his wife come from modest backgrounds, with Charles being raised by his grandmother, a former schoolteacher, and Diane coming from a rural family with a small dairy operation. They are proud of their backgrounds, and like to tell stories of their early hardships.

The company's heritage as an informal place to work has led management to take a rather hands-off approach to many areas of the operations. For example, Wilson and his top managers are knowledgeable about WM's operations, but many have not yet familiarized themselves with the software that WM uses within their respective areas of responsibility, leaving that "tech area to the tech nerds," to quote Al Winslow, Benton Harbor's general manager. Much of this software has been in use by WM for years. Charles Wilson prefers to say "We are manufacturing people, not computer geeks." WM has information technology (IT) staff in each facility who are responsible for solving hardware and software problems. Each such individual has complete administrative privileges with respect to the computer system in each facility. Management at all three facilities prefers to pay sales people's expense reports, as well as many other reimbursable purchases made by employees, out of petty cash in order to avoid making the employees go to the bank to cash the checks, and in order to keep flexibility in assigning expenditures to accounts until the last minute. Fort Wayne has $\$ 8,000$ in petty cash, while Benton Harbor and Troy each keep $\$ 6,000$ in their petty cash accounts. In the local areas surrounding each of the three plants, employees of several small retail auto part stores stop by daily to purchase needed parts and pay cash, a long-term tradition that Wilson has not been interested in changing. In each facility, the office secretary maintains the petty cash fund in a locked box kept in a lockable drawer in the desk, located in an open area between the Operations managers' office and the Chief plant Accountant's office.

The company has a reorganization/cost cutting process that is underway, and many employees are worried about losing their jobs. Morale has fallen significantly and noticeably over the past six months. The company's top managers are considering applying for another multi-million dollar loan, but are concerned that the firm's current financial conditions would not support their loan application.

The initial steps in the cost cutting plan include:

1. Suspending employee discounts for purchased parts,

2. Combining sales territories rather than hiring new sales staff for positions opened through retirement, and

3. Eliminating three of the five general and payroll accounting positions at each of the facilities. This is possible by implementing new accounting software throughout the corporation.

These steps are to be taken in the coming months. The company has already taken steps in the past twelve months such as:

1. Reducing human resource staff and requiring managers of each department to become more involved in identifying and hiring appropriate individuals and

2. For each facility, reducing shift work, eliminating third shift and curtailing second shift. Maintenance workers are still on third shift but security personnel were reduced in number from four to one for third shift and from three to one for second shift. First shift still has three security workers on hand. 
The changes have led to some bad feelings toward the company. Already, the workload of the eliminated positions that other positions have had to take on is resulting in less timely recording of asset acquisitions and disposals, as well as unscheduled maintenance costs. Additionally, there is a growing delay in the recording of both purchase returns and allowances and sales returns and allowances - at first due to implementation problems with the new accounting software, and more recently because of growing dissatisfaction of employees with their current employment situation. Generally, these transactions and quite a few others are lumped together on some employee's desk and entered every couple of weeks into the accounting information system. The company uses the periodic method for tracking inventory, with inventory shortages growing over the last two years. Many managers are blaming the inventory shortages on the implementation of the new accounting system, believing that the costing system is not recording enough scrap and that it is overstating cost of goods sold. The technicians responsible for the accounting information system have limited accounting knowledge and operate independently of the accounting department. They report system changes to the Chief Accountant and provide Accounting with reports created internally. The financial accounting personnel were very upset with the proposed cutback in their departments. Initially, they believed that the new accounting software would allow the accountants time to expand their field of responsibility, not result in a $60 \%$ reduction in staffing. Reed Taylor, CFO, has openly questioned some of the cut-cutting measures, even though he is on the budget committee responsible for creating the cut-cutting initiatives. He operates out of the Fort Wayne office, usually traveling to the other two facilities twice a year to check up with the accounting personnel and see how things are going.

Many plant employees are disgruntled over loss of the employee discount for parts. Quite a few of the employees work on their own vehicles and have utilized the employee discount program extensively over the years. Mike Keller, Warehouse Supervisor at the Troy facility, has argued frequently with Peter Olige, Operations Manager at Troy, about the lack of concern for employee morale, stating that "The company is leaving it to the supervisors to deal with the turmoil."

There are a few "bright" spots for WM in the employee morale area. Michelle Guru, the office secretary at Fort Wayne, has not missed work in 3 years, working diligently and occasionally until the mid-evening hours to get things done. She has been given more and more responsibility as she has grown and become familiar with the company's operations. In fact, because of her work ethic, the operations manager in Benton Harbor hired her cousin, Ellen Casey to work in the warehouse there. Other notable employees include; Mike Keller (Four years at WM, with no vacation during that time) as warehouse supervisor at Troy; Gracie Johnson, security ( $3 \frac{1}{2}$ years, no vacation) on third shift in Troy, and Willy Peterson, night foreman at Troy (six years, no vacation), always willing to fill in for first or second shift as needed.

WM has been fairly successful in other cost-cutting areas, reducing utilities cost by contracting with the local municipal energy supplier for lower rates seven years ago, resulting in substantial savings. Component changes in design and process have led to material costs dropping consistently over the past four years. Interest expense, insurance expense and depreciation expense are all below industry averages as a percent of sales dollar.

\section{DISCUSSION GUIDING QUESTIONS}

You are a staff auditor for the external CPA firm that is auditing WM's financial statements at year end. Please answer the following questions:

1. Are there any identifying conditions at WM that might make you concerned about asset misappropriation? If so, what are they, and why are they of concern to you?

2. What steps would you include in your audit plan in order to uncover a significant asset misappropriation, if one occurred recently at WM? 


\section{TEACHING NOTES}

The WM case contains the following warning signs of potential misappropriation of assets. These warnings are followed by the factors that auditors should consider, and what to look out for. These teaching notes are organized into different segments; each segment addresses a different general circumstance in the case that could easily contribute to the misappropriation of assets.

\section{Segment 1 - Incentives And Pressures}

The personal financial obligations of managers or employees could create pressure for them to misappropriate assets, particularly if they are in a position to do so.

1. WM CEO Wilson is quite open about his real estate holdings around North America as well as his affinity for travel. He earns $\$ 300,000$ per year, and his bonuses have never been more than $15 \%$ of that. This is curious, as no mention has been made of inheritance, and Wilson has told many people that his wife doesn't work for pay, but instead spends her time on community events and as a housewife.

a. Auditor's considerations: This situation could provide an incentive for theft or other inappropriate use of company assets. The auditors should consider the following possibilities:

i. Formation of related-party entities controlled by management, serving as paper vendors to divert profits,

ii. WM's funds may have been diverted toward the payment of personal debts,

iii. Diversion of corporate opportunities to the benefit of management or employees (e.g., offthe-book sales),

iv. Unauthorized increases in bonuses or other compensation,

v. Inflated expense reimbursements or ghost employees on payroll, and

vi. Unauthorized access to sensitive customer/vendor account information (if unauthorized individuals are accessing this information, for what purpose?).

\section{Segment 2 - Incentives And Pressures}

Adverse relationships between WM and employees with access to cash or other assets susceptible to theft might motivate those employees to misappropriate those assets. For example:

1. Many employees know that future layoffs loom. Because of this, employees (particularly nonperforming ones, or those who consider themselves prime candidates for termination) may try to make the financial statements look better by manipulating the financial information - justified as an effort to forestall layoffs. Other employees may decide to embezzle funds and/or assets in order to prepare or compensate for possible future termination. The auditors should consider the following possibilities:

a. Irregularities in Revenue, such as the premature recognition of revenue (e.g., channel stuffing, inducements to customers through bribery), sweetheart deals to customers, or the creation of fictitious revenues.

b. Inappropriate management of earnings may be present - for example, through postponement of charges such as impairment of goodwill, through inappropriate capitalization of costs, and through understatement of reserves (such as estimated warrantee liability).

c. Fraudulent dealings with WM's customers, vendors and/or lending institutions (in which case all asset and liability determinations could be questionable).

d. Misappropriation of assets. Particular attention should be paid to assets easily converted to personal recreation, company housing, automobiles, electronic equipment, etc. In addition, management might personally benefit from the use of certain vendors or the sale of company assets for personal gain. 
e. Inventory could be misappropriated. WM has raw material that is easily converted to multiple uses (e.g., ball bearings, oil, nuts and bolts, etc.).

f. Future layoffs may affect employees' propensity to act ethically (e.g., "the company doesn't want me, so why should I care about the company?"). The auditor should pay close attention to employees with access to sensitive information on customers, vendors and other employees.

g. $\quad$ Employee termination costs, if any, might be inflated.

h. Unauthorized employee benefits or increases in salary or bonuses.

i. Inflated employee expenses or ghost employees.

\section{Segment 3 - Opportunities}

Certain conditions, if present, increase the chance that employees will misappropriate assets. For example:

1. WM keeps excessively large amounts of cash on hand in all three facilities (a total of $\$ 20,000$ in petty cash). This condition, when combined with ineffective management or ineffective controls, could facilitate embezzlement (see item 5 under segment 4 below). These conditions are especially of concern in the case of the office secretary in Fort Wayne (Michelle Guru), who hasn't taken a vacation in 3 years (see item 9 under segment 4 below). The case also mentions that Ms. Guru has been given more and more responsibilities over time.

The auditor should carefully consider auditing all disbursements made from each of the three petty cash funds, paying particular attention to disbursements for which documentation is less than convincing. The auditor should also give careful consideration to opportunities that Ms. Guru's responsibilities, or those of the other petty cash custodians, might allow them to cover up possible embezzlements of petty cash - including any that might involve Ms. Guru's cousin (Ellen Casey) who works in the warehouse.

Given the recent drop in employee morale and the above factors, consideration should be given to the possibility of collusion between one or more of the petty cash custodians and one or more individuals with authority over the accounting records - e.g., records for accounts receivable, which could facilitate a lapping fraud.

2. WM has many small parts in inventory, as well as supplies with value outside the company. In addition, plant security personnel have been cut by between 67\% (during second shift) and 75\% (during third shift), potentially making the misappropriation of assets easier. The auditor should consider the possibility of theft of inventory and/or supplies, as indicated by:
a. Reduction in inventory turnover,
b. Excessive billing errors,
c. Errors made in the physical count of inventory,
d. Discrepancies between balances in the general ledger and the subsidiary ledger, and
e. An increase in vendor complaints.

\section{Segment 4 - Opportunities} For example:

Inadequate internal control over assets may increase the susceptibility of those assets to misappropriation.

1. Several WM employees have been laid off, including accounting personnel, and more layoffs are expected soon. As a result, segregation of duties may have been weakened, and it is possible that independent checks specified by WM's internal control system might be no longer being conducted. These conditions increase the risk that the financial statements are materially misstated as a result of fraud - a risk which might be considered pervasive. 
2. Because of the accounting layoffs and the new accounting software, it is possible that WM's internal control (e.g., oversight) with respect to the accountants in Troy and Benton Harbor has been weakened. This condition could facilitate embezzlement. Investigating discrepancies between the general ledger against the subsidiary ledger, reviewing vendor reports for irregularities, and checking for ghost employees in these facilities might reveal misappropriation of assets.

3. WM has significantly cut staff in the human resources department. This condition (especially when coupled with ineffective management or controls) could facilitate embezzlement or theft through the hiring of individuals with a criminal background or a history of theft or embezzlement. The auditor should consider whether the following are present:

a. Lapping schemes, as indicated by a reduction in accounts receivable turnover, excessive billing errors, trends of decreasing payments on accounts receivable, increases in customer complaints, or discrepancies between general ledger and subsidiary ledger balances,

b. Employee theft, as indicated by a decrease in inventory turnover, excessive billing errors, errors in the physical count of inventory, increases in vendor complaints, or discrepancies between general ledger and subsidiary ledger balances,

c. Fraudulent dealings with WM's customers, vendors, or lending institutions (in which case all asset and liability valuations may be questionable),

d. $\quad$ Procurement fraud (e.g., management personally benefits from the use of certain vendors, or the sale of WM assets for personal gain),

e. Unauthorized employee benefits or increases in salary or bonuses, and

f. Inflated employee expenses, or ghost employees.

The auditor should carefully consider employee access to customer, vendor, and employee accounts.

4. WM cutbacks have led to less timely (and very possibly less accurate) record keeping for assets. This condition (especially when combined with ineffective management or controls) might facilitate embezzlement or manipulation of earnings. The auditor should consider:

a. $\quad$ Employee theft, as indicated by a lowering of inventory turnover, excessive billing errors, errors in the physical count of inventory, increases in vendor complaints, or discrepancies between general ledger and subsidiary ledger balances,

b. Whether the recording of asset obsolescence or impairment, if necessary, has been adequate, and

c. Reviewing fixed asset usefulness (e.g., depreciable lives, residual values, security).

5. Physical security over petty cash in each of the three facilities is inadequate (in each facility, a locked box in a secretary's lockable desk drawer), especially given the amounts involved (a total of \$20,000). This greatly increases the chance of embezzlement, particularly given the fact that the person in charge of "petty cash" in Fort Wayne hasn't missed a day of work in three years (see item 9 below).

a. The auditor should carefully review all records related to petty cash to ensure that all cash and cash disbursements are properly accounted for.

6. The auditor should consider whether physical safeguards over inventory, investments, fixed assets and cash (other than petty cash, mentioned above) is adequate. If not, this could facilitate the misappropriation of such assets, especially when combined with ineffective management and/or weaknesses in other controls over these assets. The auditor should consider whether the following are present:

a. Employee theft, as indicated by a reduction in inventory turnover, excessive billing errors, errors in the physical count of inventory, increases in vendor complaints, or discrepancies between general ledger and subsidiary ledger balances, 
b. Inadequate recording of asset obsolescence or impairment, or fixed asset usefulness (e.g., depreciable lives, residual values, security),

c. Lapping schemes, as indicated by a reduction in accounts receivable turnover, excessive billing errors, trends of decreasing payments on accounts receivable, increase in customer complaints, and/or discrepancies between general ledger and subsidiary ledger balances,

d. Fraudulent dealings with WM's customers, vendors, or lending institutions (all asset valuations and liability determinations may be questionable),

e. $\quad$ Procurement fraud (e.g., an employee personally benefits from the use of certain vendors, or the sale of WM's assets for personal gain),

f. Unauthorized employee benefits or increases in salary or bonuses,

g. Inflated employee expenses or ghost employees, and

h. Unauthorized liquidation of investments.

7. The auditor should inquire as to how recently WM has reconciled assets with the accounting records for those assets (especially given the delays in recording, for example, purchase returns and allowances and sales returns and allowances). If these reconciliations are not being done regularly, this condition (especially when combined with ineffective management or controls) could facilitate embezzlement. The auditor should consider the following possibilities:

a. Employee theft, as indicated by a reduction in inventory turnover, excessive billing errors, errors in the physical count of inventory, increases in vendor complaints, or discrepancies between general ledger and subsidiary ledger balances,

b. Inadequate recording of asset obsolescence or impairment, or fixed asset usefulness (e.g., depreciable lives, residual values, security),

c. Lapping schemes, as indicated by a reduction in accounts receivable turnover, excessive billing errors, trends of decreasing payments on accounts receivable, increases in customer complaints, or discrepancies between general ledger and subsidiary ledger balances,

d. Fraudulent dealings with WM's customers, vendors, or lending institutions (all asset valuations and liability determinations may be questionable),

e. $\quad$ Procurement fraud (e.g., an employee personally benefits from the use of certain vendors, or the sale of WM's assets for personal gain),

f. Unauthorized employee benefits or increases in salary or bonuses, inflated employee expenses or ghost employees,

g. Unauthorized liquidation of investments or other assets, and

h. Unauthorized discounts for employee purchases.

8. WM has become slow in recording both purchase returns and allowances and sales returns and allowances. Accountants at all three facilities group these transactions together and enter them into the system every couple of weeks or so. This situation could be indicative of earnings manipulation or embezzlement. The auditor should consider whether the following are present:

a. Premature recognition of revenue (e.g., channel stuffing, inducement to customers through bribery) or the creation of fictitious revenue (e.g., unrecorded sales returns or allowances),

b. Inappropriate management of earnings (often performed through postponement of charges such as impairment of goodwill, capitalization of expenses, understatement of reserves such as estimated warrantee expense, and failure to adequately accrue potential employee termination costs). Transactions other than sales or purchase returns and allowances might not be recorded in a timely manner, or at all,

c. Fraudulent dealings with WM's customers, vendors, or lending institutions (all asset valuations and liability determinations may be questionable),

d. Misappropriation of assets (e.g., an employee personally benefits from the use of certain vendors, or the sale of WM assets for personal gain),

e. Unauthorized employee benefits or increases in salary or bonuses, and 
f. Inflated employee expenses or ghost employees. accounts.

The auditor should give special consideration to employee access to customer, vendor and employee

9. WM has several employees (known for their "work ethic") who have not taken vacation time in years. This is an important warning sign to auditors, particularly when the employee in question performs key control functions (e.g., maintaining custody of cash, as is the case with Michelle Guru), and could facilitate embezzlement. ${ }^{1}$ The auditor should:

a. Consider the responsibilities of individuals who have not taken vacation time in the past year, and whether those responsibilities allow for the concealment of embezzlement and a reduction in the likelihood of an embezzlement being detected,

b. Explain to top management why it's important that all employees take at least some vacation time, and

c. Consider possible embezzlement schemes that could be perpetrated by employees who have not taken vacation time in the past year (e.g., lapping, kiting), and perform tests to uncover them.

10. WM's CEO has stated on several occasions that he doesn't understand many of WM's software programs, and apparently is not terribly concerned about the fact that many of his top managers have not yet developed any real competence in this area as well. "We are manufacturing people, not computer geeks", is a wellknown comment of his. This condition could allow WM's internal controls to be compromised, could allow its information technology employees to misappropriate assets, and reduces the likelihood of fraud being detected.

a. The auditor should carefully consider employee access to customer, vendor and employee accounts in connection with procurement or payroll and benefit fraud.

b. The auditor should carefully consider the ways in which WM's internal controls, asset security, and financial statement integrity could be compromised by this condition.

11. Each of WM's IT workers has complete administrator privileges over each facility's computer system. This provides inadequate control over system access and event logs.

a. This condition could indicate that the financial statements have been materially misstated as a result of fraud (and might be considered a pervasive risk).

\section{Segment 5 - Attitudes And Rationalizations}

Attitudes and rationalizations on the part of those with access to assets susceptible to misappropriation.

1. WM's management has shown little apparent concern for the internal control weaknesses (e.g., reduction or elimination of separation of duties) brought about by staff cutbacks.

a. This condition facilitates the embezzlement of assets without the likelihood of being detected.

2. The CEO's lifestyle (five homes, several in expensive markets; affinity for travel) might be beyond his means $(\$ 300,000$ salary plus bonus; wife doesn’t work for pay).

\footnotetext{
${ }^{1}$ The reason she hasn't taken a vacation in three years may be that if she has perpetrated a fraud, letting some else take over her duties while she is on vacation could result in the discovery of the fraud, as in a lapping or kiting scheme.
} 
a. This condition could be an indication that the financial statements have been materially misstated as a result of fraud (and may be considered a pervasive risk, especially since the employee involved is the CEO).

3. Ill will on the part of WM workers toward the company, brought about by layoffs, increased responsibilities and reduction in benefits (e.g., employee discounts) provides a rationalization for wrongdoing.

The auditor should consider the following:

a. Embezzlement schemes created through internal control weaknesses and through overriding existing controls, especially in such key areas as purchasing, payments, receiving, sales revenues and cash receipts, and

b. Ways in which the financial statements could be misstated in an effort to cover up such schemes.

\section{SUMMARY}

This paper presents a teaching case, Wayne Manufacturing, intended for use in an undergraduate auditing or fraud examination course. Wayne Manufacturing (WM) has a number of conditions that put it at risk for misappropriation of assets, as well as for a cover-up of the misappropriation through fraudulent financial reporting. Students are asked to put themselves in the position of WM's auditor, and identify these conditions of concern, and indicate how those conditions would impact their audit. Teaching notes are organized into categories such as Incentives and Pressures, Opportunities, and Attitudes and Rationalizations.

\section{NOTES}




\section{NOTES}

